\title{
A phase I study of bendamustine hydrochloride administered day $1+2$ every 3 weeks in patients with solid tumours
}

\author{
M Rasschaert ${ }^{1,5}$, D Schrijvers², J Van den Brande', J Dyck', J Bosmans ${ }^{3}, K_{\text {Kerkle }}^{4}$ and JB Vermorken*,I \\ 'Department of Medical Oncology, University Hospital Antwerp, Wilrijkstraat 10, 2650 Edegem, Belgium; ${ }^{2}$ Department of Medical Oncology, ziekenhuis \\ netwerk Antwerpen - Middelheim, Lindendreef IB, 2020 Antwerpen, Belgium; ${ }^{3}$ Department of Cardiology, University Hospital Antwerp, Wilrijkstraat 10 , \\ 2650 Edegem, Belgium; ${ }^{4}$ Clinical Research, Ribosepharm GmbH, Munich, Germany
}

The aim of the study was to determine the maximum tolerated dose (MTD), the dose limiting toxicity (DLT), and the pharmacokinetic profile $\left(\mathrm{P}_{\mathrm{k}}\right)$ of bendamustine (BM) on a day I and 2 every 3 weeks schedule and to recommend a safe phase II dose for further testing. Patients with solid tumours beyond standard therapy were eligible. A 30-min intravenous infusion of BM was administered $\mathrm{dl}+\mathrm{d} 2 \mathrm{q} 3$ weeks. The starting dose was $120 \mathrm{mg} \mathrm{m}^{-2}$ per day and dose increments of $20 \mathrm{mg} \mathrm{m}^{-2}$ were used. Plasma and urine samples were analysed using validated high-performance liquid chromatography/fluorescence assays. Fifteen patients were enrolled. They received a median of two cycles (range I -8). The MTD was reached at the fourth dose level. Thrombocytopaenia (grade 4) was dose limiting in two of three patients at $180 \mathrm{mg} \mathrm{m}^{-2}$. One patient also experienced febrile neutropaenia. Lymphocytopaenia (grade 4) was present in every patient. Nonhaematologic toxicity including cardiac toxicity was not dose limiting with this schedule. Mean plasma $P_{k}$ values of BM were $t_{\max } 35 \mathrm{~min}, t_{1 / 2} 49.1 \mathrm{~min}, V_{d} 18.31 \mathrm{~m}^{-2}$, and clearance $265 \mathrm{ml} \mathrm{min}^{-1} \mathrm{~m}^{-2}$. The mean total amount of BM and its metabolites recovered in the first micturition was $8.3 \%$ (range 2.7-26\%). The MTD of BM in the present dose schedule was $180 \mathrm{mg} \mathrm{m}^{-2}$ on day $1+2$. Thrombocytopaenia was dose limiting. The recommended dose for future phase II trials with this schedule is $160 \mathrm{mg} \mathrm{m}^{-2}$ per day.

British Journal of Cancer (2007) 96, 1692-1698. doi:I0.1038/sj.bjc.6603776 www.bjcancer.com

Published online 8 May 2007

(c) 2007 Cancer Research UK

Keywords: bendamustine; day I + 2 schedule; pharmacokinetics; phase I

The cytotoxic agent bendamustine (BM) hydrochloride (Cytosan ${ }^{\circledR}$, Treanda ${ }^{\circledR}$, Ribomustin ${ }^{\circledR}$, IMET-3393; ZIMET-3393; 5-[bis(2-chloroethyl)amino]-1-methylbenzimidazolyl-2-butyric-acid) is a multifunctional alkylating agent with a purine-like ring system and a novel mechanism of action. Ozegowski and Krebs (1963) first synthesised it in 1963 in former Eastern Germany. Owing to a hydrochloride residue to the butyric acid side chain, $\mathrm{BM}$ is soluble in water (Gandhi, 2002). Its alkylating activity has been described in preclinical studies, where - at least in high dosages - it causes the formation of intrastrand and interstrand crosslinks between DNA bases (Gandhi, 2002). In comparison with other more commonly used alkylating agents, such as cyclophosphamide or phenylalanine mustard, more DNA double-strand breaks are formed when used in equitoxic dosages (Barmam Balfour and Goa, 2001). In addition, DNA damage produced by BM is supposed to be repaired via baseexcision repair rather than the alkylguanine transferase mechanism (Niemeyer et al, 2004). This suggests a different mode of action, which was recently confirmed when gene expression profiling analysis identified a different gene profile activated by BM (Leoni et al, 2004; Niemeyer et al, 2004). It offers an explanation for the

\footnotetext{
*Correspondence: Dr JB Vermorken; E-mail: jan.b.vermorken@uza.be

${ }^{5}$ Current address: Oncologisch Centrum GVA, Oosterveldlaan 24, 2610 Wilrijk.
}

Received 25 January 2007; revised 12 April 2007; accepted 12 April 2007; published online 8 May 2007 lack of cross-resistance with other alkylating agents, as observed in anthracycline-resistant breast cancer cell lines and cisplatinresistant ovarian cancer cell lines (Strumberg et al, 1996). Treatment with BM also induces a concentration-dependent apoptosis as evidenced by changes in Bcl-2 and Bax expression profiles in chronic B-cell lymphocytic leukaemia (Konstantinov et al, 2002; Schwänen et al, 2002). Synergism was demonstrated when BM was combined with fludarabine (Chow et al, 2001). Further evaluation indicated that the synergistic effects were associated with the downregulation of inhibitors of apoptosis proteins, prostateapoptosis-response-gene 4, and death-associated protein (Daxx) and with enforced caspase activation (Chow et al, 2003).

Preclinical studies indicated that BM is selectively taken up from the plasma in the liver where it undergoes extensive first pass metabolism involving conjugation with glutathione (Bezek et al, 1996; Teichert et al, 2005). Similar to other mustards containing the bis-chloroethyl moiety, two products of chemical hydrolysis, namely monohydroxy-bendamustine (OH-BM) and dihydroxy-bendamustine (Di-OH-BM), have been detected. The elimination of unchanged BM and these metabolites is primarily renal (Weber et al, 1991; Preiss et al, 1998; Teichert et al, 2003). However, the main biotransformation products $\mathrm{N}$-dimethyl-BM and $\gamma-\mathrm{OH}-\mathrm{BM}$ are excreted with the bile (Bezek et al, 1991; Preiss et al, 1998; Teichert et al, 2006). In preclinical studies, acute toxicity is observed in bone marrow and intestines, while the kidneys, testes, prostate, and the lymphatic tissues are prone to subacute toxicity (Horn et al, 1985). 
After its preclinical development, BM was first tested in multiple myeloma in 1969 and went into clinical use from 1971 onwards. After Germany's reunification, BM was marketed in the whole country on the basis of a so-called 'fictitious' registration. As a result of a re-registration procedure in Germany, the first full registration was granted in 2005 . Only recently the drug was rediscovered in the United States and a whole range of preclinical and clinical trials were initiated. Just now clinical trials are being started in Japan. Especially, its antilymphoma activity and the lack of complete cross-resistance with the other alkylators fuels ongoing scientific interest.

Previous phase II studies of monotherapy BM demonstrated impressive remission rates combined with good tolerability in relapsing and/or refractory non-Hodgkin's lymphoma (NHL) (Heider and Niederle, 2001; Bremer, 2002; Weidmann et al, 2002; Friedberg et al, 2004). Moreover, in combination with vincristine and prednisone (BOP), BM demonstrated higher 5-year survival rates (61 vs 46\%) compared to cyclophosphamide containing standard regimen (Herold et al, 2006). Furthermore, the doublet $\mathrm{BM} /$ rituximab is evaluated in NHL because of its synergistic activity and high response rate $(70 \%)$ in phase II trials (Kanekal et al, 2004; Rummel et al, 2005a, b). Bendamustine is also actively investigated in multiple myeloma where the combination with prednisone proved to be more efficacious than the standard treatment: melphalan and prednisone (time to treatment failure: 14 vs 10 months, $P=0.02$ ) (Pönisch et al, 2006). In solid tumours, BM's lack of cross-resistance with other alkylating agents, its favourable toxicity profile, and the fact that it shows anticancer activity in second line and in the salvage setting in patients with pretreated metastatic breast cancer (MBC) (Höffken et al, 1998; Zulkowski et al, 2002), non-small cell lung cancer (NSCLC) (Reck et al, 1998), and small cell lung cancer (SCLC) (Schmittel et al, 2007) make it a valuable addition to the armamentarium of active anticancer drugs. Recently, a randomised phase III study compared cyclophosphamide, methotrexate, and 5-fluorouracil (CMF) with a comparable schedule in which cyclophosphamide was replaced by BM (BMF). The BMF schedule demonstrated superior progression-free survival in first-line MBC (8.2 vs 6.7 months for CMF; Von Minckwitz et al, 2005).

The earlier studies suggested a variety of schedules in which single agent BM could be used: that is, as a short intravenous infusion of $50-60 \mathrm{mg} \mathrm{m}^{-2}$ for 5 consecutive days every 4 weeks; $120 \mathrm{mg} \mathrm{m}^{-2}$ for 2 consecutive days every 3-4 weeks or $60 \mathrm{mg} \mathrm{m}^{-2}$ weekly. The most commonly observed toxicities were both haematologic (leukocytopaenia, thrombocytopaenia, lymphocytopaenia, and anaemia), and nonhaematologic, in particular gastrointestinal disturbances (nausea, vomiting, and mucositis) (Schrijvers and Vermorken, 2002). Some cardiac toxicity was also described, consisting primarily of intermittent tachycardia (Reck et al, 1998; Schöffski et al, 2000a, b).

Only recently formal phase I testing resumed. These included a day $1+8$ q 4 weeks schedule, a weekly schedule, a day $1 \mathrm{q} 3$ weeks schedule - all in solid tumour patients - and a day $1+2$ q 3-4 weeks in B-cell CLL (Bergmann et al 2005; Lissitchkov et al, 2006; Rasschaert et al, 2007; Schöffski et al, 2000a, b).

The present report summarises the toxicity and pharmacokinetic profile $\left(\mathrm{P}_{\mathrm{k}}\right)$ of $\mathrm{BM}$ with the latter schedule when used in patients with solid tumours with the aim to define maximum tolerated dose (MTD), dose-limiting toxicity (DLT) and to recommend more precisely a safe dose for future phase II studies with this schedule.

\section{PATIENTS AND METHODS}

\section{Patient selection}

Patients with histologically confirmed advanced cancer refractory to standard therapy or for which no standard therapy existed were eligible. Patients were adult individuals, legally competent, in a reasonably good general condition (World Health Organization (WHO) performance status $0-2$ ), with a life expectancy of $>3$ months, and were included after obtaining informed consent. Those with disturbed liver function (aspartate (AST), alanine aminotransferases (ALT), and bilirubin $>2$ times the upper limit of normal values), disturbed renal function (serum creatinine $>2 \times \mathrm{ULN})$, inadequate bone marrow function $\left(\mathrm{Hb} \leqslant 8.0 \mathrm{~g} \mathrm{dl}^{-1}\right.$, WBC $\leqslant 4.0 \times 10^{9} 1^{-1}$, platelets $\left.\leqslant 100 \times 10^{9} 1^{-1}\right)$, inadequate cardiac function (left ventricular ejection fraction (LVEF) $<50 \%$ ), those with evidence of active infection or uncontrolled infection, epilepsy, or peptic ulcer and those with suspected central nervous system involvement were excluded from the study.

All patients provided signed informed consent. In accordance with the Declaration of Helsinki, International Conference on Harmonization - Good Clinical Practice (ICH-GCP) - guidelines and applicable local laws. The Ethics Committee of the University Hospital of Antwerp approved the protocol.

\section{Study design}

This was a single-centre, open-label nonrandomised phase I trial to study the $P_{k}$ and to define the safety and tolerability of $B M$ hydrochloride administered by a day $1+2$ every 3 weeks schedule.

Starting dose was $120 \mathrm{mg} \mathrm{m}^{-2}$ per day and dose increments of $20 \mathrm{mg} \mathrm{m}^{-2}$ per day were used, provided that no dose-limiting event occurred in the first cycle of the previous dose level. The study treatment was administered on an outpatient basis.

The individual treatment was continued until disease progression or unacceptable toxicity. Anti-emetic therapy was left to the discretion of the clinician treating the patient. The concomitant use of other cytotoxic or experimental agents was not permitted and haematopoietic growth factors (G-CSF, GM-CSF or erythropoietin) were not routinely given.

The study drug was supplied by Ribosepharm $\mathrm{GmbH}$ (Munich, Germany) in sterile vials containing $100 \mathrm{mg}$ BM hydrochloride to be administered in $500 \mathrm{ml}$ of $0.9 \%$ saline over $30 \mathrm{~min}$ as a peripheral or central intravenous infusion.

\section{Definition of DLT, MTD and schedule of dose escalation}

Dose-limiting toxicity was defined as (1) any $\geqslant$ grade 3 nonhaematologic toxicity (except for alopecia and inadequately treated nausea or vomiting), (2) grade 4 anaemia or thrombocytopaenia, (3) leukopaenia $\left(<1.5 \times 10^{9} 1^{-1}\right)$ or thrombocytopaenia $\left(<50 \times 10^{9} 1^{-1}\right)$ for $>14$ days (lymphocytopaenia was not considered dose limiting), or (4) febrile neutropaenia.

Initially, three patients were to be included at each dose level. If no DLT developed, dose escalation would continue. If one of three patients developed a DLT, another three would be enrolled at that same dose level. If at least two of three patients or at least two of six patients developed an identical DLT, that dose level would be classified as the MTD. If no more than one of six patients developed DLT, dose escalation would proceed.

No intra-patient dose escalation was permitted. Once three patients completed the first cycle defined as 21 days after the first BM administration and had been observed for acute toxicity, patients were allowed to start treatment at the next dose level.

\section{Assessment of toxicity}

Patients were assessable for safety analysis when at least one cycle was administered and when one observation was carried out afterwards. Monitoring of safety and tolerability was carried out by the National Cancer Institute of Canada, Common Toxicity Criteria (NCIC-CTC version December 1994). The evaluation of side effects was based on weekly outpatient visits with laboratory and clinical investigations, medical history, and a full physical 
examination. The following investigations were carried out before each cycle: toxicity assessment; physical examination, including heart rate, blood pressure, body temperature, and body weight; blood tests including blood sedimentation rate, coagulation parameters, differential blood count, serum analysis including sodium, potassium, calcium, creatinine, blood urea nitrogen (BUN), uric acid, AST and ALT, alkaline phosphatase, $\gamma$-glutamyl transpeptidase, lactate dehydrogenase, bilirubin, creatine kinase (CK), CK-MB, protein, albumin, c-reactive protein, glucose, and tumour markers. Urinalysis, urinary sediment, and creatinine clearance (calculated by Cockroft-Gault equation) were also evaluated.

Toxicity assessment, physical examination, pulse rate, differential blood count, and serum parameters (creatinine, BUN, AST, ALT, CK, CK-MB, and glucose) were repeated weekly.

For the assessment of potential cardiac toxicity, electrocardiograms (ECG) were performed on days 1 (before and after treatment administration), 2, 8, and 15 of each cycle. Left ventricular ejection fraction (LVEF) (evaluated by MUGA scan) was initially determined only before the first administration of BM. However, when we observed cardiac toxicity in another phase I study using a day 1 q 3 weeks schedule, which was running in our department at the same time (Rasschaert et al, 2007), the study was put 'on hold' after recruitment of six patients (three each in dose levels 120 and $140 \mathrm{mg} \mathrm{m}^{-2}$ ). Only after the other phase I trial was completed, the protocol was amended for evaluating the LVEF every other cycle and recruitment resumed. In addition, we assessed troponin-t, prothrombotic parameters (platelet function, aggregation tests (with ristocetine, collagen, epinephrine)) and clotting factors (eg, Von Willebrand antigen) in a subset of patients. Furthermore, the wall tracking system was used to assess flow-mediated and nitroglycerin-mediated vasodilation of the brachial artery as described previously (Pyke and Tschakovsky, 2005). These parameters determine endothelial function and by themselves have been correlated to exercise tolerance and coronary heart disease.

\section{Assessment of response}

Response was assessed every other cycle. For this, WHO criteria were used: complete response, complete disappearance of tumour and signs, or symptoms of disease; partial response, $>50 \%$ reduction in tumour (calculated as the product of the tumour's greatest diameter and its perpendicular measurement) for a minimum of 4 weeks; minimal response, $25-50 \%$ reduction in tumour for a minimum of 4 weeks; stable disease (SD), $<25 \%$ reduction or $<25 \%$ progression for a minimum of 4 weeks; and progressive disease $(\mathrm{PD}),>25 \%$ increase in tumour size.

\section{Pharmacokinetics}

Plasma samples Five millilitres ( $\mathrm{ml}$ ) venous whole blood was drawn on day 1 , from the arm contralateral to the infusion arm into $7.5 \mathrm{ml}$ monovettes containing lithium heparin at the following time points: 0 (predose baseline), 10, 20, 30 (end of infusion), 35, $40,45,50,60,75,90,105,120,180,280,360$, and $480 \mathrm{~min}$.

Immediately upon collection, the samples were transferred in ice water and spun in a cold $\left(4-6^{\circ} \mathrm{C}\right)$ centrifuge at $2000 \mathrm{~g}$ for $4 \mathrm{~min}$. The separated plasma was immediately deep-frozen at $-70^{\circ} \mathrm{C}$ in three aliquots of approximately $0.8 \mathrm{ml}$ in prelabelled $1.2 \mathrm{ml}$ tubes (Nalgene, Nalge Nune International, Rochester, NY, USA).

Urine samples Before the first treatment (on the day before or on the treatment day), a $2 \mathrm{ml}$ predose urine sample was collected from each patient. The urine produced after starting the drug infusion (first micturition) was completely collected throughout cycles 1 and 2. Two $1 \mathrm{ml}$ aliquots of each collection were stored at $-70^{\circ} \mathrm{C}$.

Plasma and urine samples were analysed using a validated highperformance liquid chromatography/fluorescence assay.
Pharmacokinetic evaluation Pharmacokinetic calculations were performed by means of the pharmacokinetic software package WinNonlin Pro 4.0 (Pharsight Corporation, USA, 2002). Parameters were determined by non-compartmental analysis (NCA).

The NCA was based on a model requiring a constant infusion of the drug. The peak plasma concentration $\left(C_{\max }\right)$ and the time to reach $C_{\max }\left(t_{\max }\right)$ were read directly from the concentration-time data. The area under the plasma concentration-time curve (AUC) was calculated by the trapezoidal method from the first to last measurable concentration and extrapolated to infinity $\left(\mathrm{AUC}_{\mathrm{Inf}}\right)$ using the ratio of the last measured concentration to the terminal slope. The latter was determined by log-linear regression analysis of the terminal phase. Clearance and volume of distribution $\left(V_{\mathrm{d}}\right)$ were normalised to body surface area.

\section{Statistical analyses}

Interpretation of the clinical data was by SPSS 11.5 statistical software (SPSS Inc., Chicago IL, USA); only descriptive statistics are given.

Results are presented in absolute numbers or as group medians with the range or mean values with standard deviation (s.d.) or standard error (s.e.) as indicated.

\section{RESULTS}

\section{Patient characteristics}

A total of 15 patients were enrolled in this phase I trial over an extended time period (September 2000 to December 2003). Their characteristics are summarised in Table 1. The median WHO performance status of these patients was 1 (range $0-2$ ).

All patients had received prior treatment for metastatic or recurrent disease and were refractory to prior chemotherapy. The median number of prior chemotherapy regimens was 3 (range 1-5 regimens); in fact, 12 of the 15 patients had received 3 or more chemotherapeutic regimens. None of the patients had received BM before.

\section{Bendamustine administration}

A total of 35 cycles were administered with a median of 2 cycles (range 1-8). Five patients received only two cycles; of the patients who received three or more cycles, one received four cycles, one six cycles and one eight cycles. All patients received the full planned dose and no dose reductions were needed.

Of the seven patients who stopped treatment after one cycle, three patients did not complete the first observation period of 21 days and underwent surgery for PD. Four patients stopped therapy after one cycle, and did not receive a second because of death owing to tumour progression (1), refusal (1), PD (1) and one patient stopped treatment because of dose-limiting haematologic toxicity.

Only two cycles were delayed. In one case (second cycle at $160 \mathrm{mg} \mathrm{m}^{-2}$ ) this was due to haematologic toxicity (thrombocytopaenia maximally grade 3 but no DLT). In the second case (sixth cycle at $160 \mathrm{mg} \mathrm{m}^{-2}$ ), this was carried out on request of the patient.

\section{Safety}

The worst nonhaematologic and haematologic toxicities per patient experienced during the first cycle are shown in Table 2. No treatment-related deaths occurred.

Nonhaematologic toxicity Nonhaematologic toxicity was generally mild and not dose-limiting. The most frequently encountered side effects were fatigue (13 patients $-87 \%$ ), nausea (10 patients - 
$67 \%)$, loss of appetite (10 patients $-67 \%)$, and vomiting (8 patients $-53 \%)$.

One patient developed a grade 2 allergic reaction after the administration of $\mathrm{BM}$ at a dose of $140 \mathrm{mg} \mathrm{m}^{-2}$. He experienced shortness of breath with mild stridor, flushes, and tachycardia. All effects were reversible after drug administration was interrupted (day 1 of the first cycle of BM); the second dose (day 2) could be completed uneventfully following a slow infusion rate and the use

Table I Patient characteristics

\begin{tabular}{|c|c|}
\hline & Number of patients $(n=15)$ \\
\hline \multicolumn{2}{|l|}{ Gender } \\
\hline Male & 8 \\
\hline Female & 7 \\
\hline \multicolumn{2}{|l|}{ Age } \\
\hline Median (years) & 55 \\
\hline Range (years) & $29-80$ \\
\hline \multicolumn{2}{|l|}{ WHO performance status } \\
\hline 0 & 2 \\
\hline 1 & 8 \\
\hline 2 & 5 \\
\hline \multicolumn{2}{|l|}{ Pretreatment } \\
\hline Immunotherapy & 3 \\
\hline Chemotherapy & 15 \\
\hline Surgery & 14 \\
\hline Radiation & 5 \\
\hline \multicolumn{2}{|l|}{ Tumour type } \\
\hline Colorectal carcinoma & 4 \\
\hline Soft tissue sarcoma & 3 \\
\hline Renal cell cancer & 2 \\
\hline Melanoma & 2 \\
\hline Oesophageal cancer & 1 \\
\hline Adrenocortical carcinoma & I \\
\hline Osteosarcoma & I \\
\hline Mesothelioma & I \\
\hline
\end{tabular}

of corticosteroids prophylactically. No alopecia or peripheral neuropathy was observed.

None of the eligible patients had clinically relevant coronary heart disease; however four patients entered the study with abnormal ECGs: one showed a right bundle branch block, the second a left anterior fascicular block, the third a first degree atrioventricular block, only one - the fourth showed non-specific Twave abnormalities. Serial ECGs were performed according to protocol and showed cardiac toxicity. Sinus tachycardia (grade 1 NCI-CTC) was present in four patients (one patient at 120, one at 140 , and two at $160 \mathrm{mg} \mathrm{m}^{-2}$ ). Premature supraventricular complexes were seen in one patient at $140 \mathrm{mg} \mathrm{m}^{-2}$ and premature atrial complexes and ventricular extrasystoles were observed in another patient at $160 \mathrm{mg} \mathrm{m}^{-2}$. No therapeutic intervention was needed. Furthermore, one patient (at $140 \mathrm{mg} \mathrm{m}^{-2}$ ) with a left anterior fascicular block before study entry developed ECG signs compatible with an infero-septal infarction on day 22 of the first cycle, at which time he was hospitalised because of gastro-intestinal bleeding and generalised malaise. Since no clinical symptoms of acute myocardial infarction or elevated CK/CK-MB were recorded, the ECG changes were evaluated as disease related (due to anaemia).

However, since ischaemic cardiac toxicity was observed in our day 1 every 3 weeks phase I study with the same drug, an analysis was performed in four patients at dose level $160 \mathrm{mg} \mathrm{m}^{-2}$ to identify any endothelial risk factors (see assessment of toxicity). No definitive relation between any of the tested parameters, use of the study drug and endothelial (dys-) function or cardiac ischaemia could be demonstrated. Furthermore, only one patient showed a decrease in LVEF (of 11\%) after the second cycle. Unfortunately, none of the patients at the higher dose level $\left(180 \mathrm{mg} \mathrm{m}^{-2}\right)$ received more than one cycle; therefore no additional information on potential cardiotoxic effects at this higher dose could be obtained.

In conclusion, cardiac toxicity in this phase I study was present, but not considered as being dose limiting. All cases of sinus tachycardia were of mild/moderate severity and self-limiting.

Haematologic toxicity Three patients presented with tumourrelated anaemia $\left(\mathrm{Hb}<10 \mathrm{~g} \mathrm{dl}^{-1}\right)$ before treatment. Two of them

Table 2 Incidence of selected adverse events: first cycle, all causalities

\begin{tabular}{|c|c|c|c|c|}
\hline Grade (NCIC-CTC) & $\begin{array}{c}120 \mathrm{mg} \mathrm{m}^{-2}(n=3) \\
\text { All/grade 3-4 }\end{array}$ & $\begin{array}{c}140 \mathrm{mg} \mathrm{m}^{-2}(n=3) \\
\text { All/grade } 3-4\end{array}$ & $\begin{array}{c}160 \mathrm{mg} \mathrm{m}^{-2}(n=6) \\
\text { All/grade } 3-4\end{array}$ & $\begin{array}{c}180 \mathrm{mg} \mathrm{m}^{-2}(n=3) \\
\text { All/grade } 3-4\end{array}$ \\
\hline \multicolumn{5}{|l|}{ Blood/bone marrow } \\
\hline Platelets & $1 / 0$ & $2 / 0$ & $3 / 0$ & $3 / 2$ \\
\hline Leukocytes & $0 / 0$ & $1 / 0$ & $3 / 0$ & $2 / 1$ \\
\hline Neutrophils & $0 / 0$ & $0 / 0$ & $1 / 0$ & |/ | \\
\hline Lymphocytes & $3 / 3$ & $3 / 3$ & $6 / 6$ & $3 / 3$ \\
\hline \multicolumn{5}{|l|}{ Constitutional symptoms } \\
\hline Fatigue & $2 / 1$ & $3 / 1$ & $4 / 0$ & $1 / 0$ \\
\hline Allergy & $0 / 0$ & $0 / 0$ & $0 / 0$ & $1 / 0$ \\
\hline \multicolumn{5}{|l|}{ Gastrointestinal } \\
\hline Nausea & $3 / 0$ & $2 / 0$ & $2 / 0$ & $2 / 0$ \\
\hline Vomiting & $2 / 0$ & $2 / 0$ & $1 / 0$ & $1 / 0$ \\
\hline Dry mouth & $0 / 0$ & $0 / 0$ & $1 / 0$ & $1 / 0$ \\
\hline \multicolumn{5}{|l|}{ Cardiovascular symptoms } \\
\hline Deep vein thrombosis & |/| & I/I & $0 / 0$ & $0 / 0$ \\
\hline Tachycardia & $1 / 0$ & $1 / 0$ & $2 / 0$ & $0 / 0$ \\
\hline
\end{tabular}


received a blood transfusion and one used darbepoetine before the start of the first cycle (protocol violation). Eight patients developed anaemia (two at $120 \mathrm{mg} \mathrm{m}^{-2}$, one at $140 \mathrm{mg} \mathrm{m}^{-2}$, three at $160 \mathrm{mg} \mathrm{m}^{-2}$, and two at $180 \mathrm{mg} \mathrm{m}^{-2}$ ) for which blood transfusions were given in seven patients.

Myelosuppression, in particular thrombocytopaenia, was dose limiting (Table 2). Thrombocytopaenia grade 4 occurred in two patients at $180 \mathrm{mg} \mathrm{m}^{-2}$. It presented late during the first cycle (nadir on days 22 and 28, respectively) and was long-lasting (18 and 11 days, respectively). Both patients suffered from soft tissue sarcoma and had been extensively pretreated with alkylating agents; one had also received radiotherapy. One of these two patients also experienced febrile neutropaenia.

With two out of three patients at the $180 \mathrm{mg} \mathrm{m}^{-2}$ dose level having thrombocytopaenia grade 4 , this dose level was defined as the MTD. The dose level of $160 \mathrm{mg} \mathrm{m}^{-2}$ was safely administered to six patients; the latter dose therefore was defined as the recommended dose for phase II studies.

Lymphocyte depletion (grade 4) was present in every patient on day 8 and at any dose level. Although lymphocyte depletion was long-lasting, no opportunistic infections were observed. However, six patients needed antibiotics for symptomatic infections (cystitis (2), streptococcal sepsis (1), acute bronchitis (1), fever of unknown origin (1), febrile neutropaenia (1)).

\section{Tumour response}

No clinical or radiologic responses were observed in these patients. However, four patients had stable disease for variable periods of time.

One patient with a soft tissue sarcoma and one with renal cell cancer, treated at the 160 and $140 \mathrm{mg} \mathrm{m}^{-2}$ dose level, respectively, experienced stabilisation of disease during six and eight cycles. A third patient with renal cell cancer, treated at the $120 \mathrm{mg} \mathrm{m}^{-2}$ dose level, had stable disease after four cycles, but stopped therapy owing to a streptococcal sepsis. A fourth patient with colorectal cancer achieved a stable disease after two cycles at $160 \mathrm{mg} \mathrm{m}^{-2}$ but refused further therapy.

\section{Pharmacokinetic profile}

The pharmacokinetic parameters of BM in plasma calculated by NCA are listed in Table 3. Plasma $P_{k}$ data were available for only six patients while urine $P_{k}$ data were available for five patients.

The mean elimination half-life of BM in plasma was $49.1 \mathrm{~min}$, the volume of distribution $18.31 \mathrm{~m}^{-2}$ and the clearance $265 \mathrm{ml} \mathrm{min}^{-1} \mathrm{~m}^{-2}$. These figures do not significantly differ from those observed in our day 1 q 3 weeks study (Rasschaert et al, 2007). Maximum plasma concentrations of BM were found at the end of the infusion. In the present study, all mean values of $t_{\max }$ and $t_{1 / 2}$ estimated for the metabolites OH-BM, $\gamma-\mathrm{OH}-\mathrm{BM}$ and
$\mathrm{N}$-dimethyl-BM were in the range of 35-64 min, and did not demonstrate a clear dose dependency.

Owing to low concentrations (below detection level) and interfering peaks, only limited $\mathrm{P}_{\mathrm{k}} \mathrm{s}$ could be drawn for Di-OHBM. Therefore, no complete pharmacokinetic evaluation was feasible for this metabolite.

\section{Urinary excretion of $\mathrm{BM}$ and its metabolites}

About $93.5 \%$ of the amount excreted in urine was BM and its hydrolysis products, expressed as the sum of parent compound and all identified metabolites. The mean total amount of BM and its metabolites recovered in the first micturition was $8.3 \%$, ranging from 2.7 to $26.0 \%$, expressed as percentage of the administered dose.

\section{DISCUSSION}

In this phase I study with $\mathrm{BM}$ hydrochloride given by a $30 \mathrm{~min}$ intravenous infusion for two consecutive days every 3 weeks, thrombocytopaenia grade 4 was the DLT at $180 \mathrm{mg} \mathrm{m}^{-2}$ per day. Other important toxicities were long-lasting lymphocytopaenia, observed from the first cycle onwards and present in every patient irrespective of the given dose, and some nonhaematologic toxicity, that is, fatigue, loss of appetite, nausea and vomiting.

The recommended dose for further phase II testing is $160 \mathrm{mg} \mathrm{m}^{-2}$ day. At this and lower doses, tachycardia was observed; however, this did not seem to be of clinical relevance. An analysis in a subset of four patients, at dose level $160 \mathrm{mg} \mathrm{m}^{-2}$, gave no evidence of platelet dysfunction or endothelial dysfunction, which could be attributed to the use of BM.

Overall toxicity has been quite similar in the different phase I studies performed with BM in patients with solid tumours. However, some schedule dependency has been noted.

In a day $1+8$ q 3 weeks schedule, Schöffski et al (2000a) determined an MTD at $140 \mathrm{mg} \mathrm{m}^{-2}$, and reported fatigue and dry mouth as DLTs. They also observed a high incidence of lymphocytopaenia without opportunistic infections. Later the same investigators conducted a phase I study of weekly BM (Schöffski et al, 2000b) and reported an MTD of $80 \mathrm{mg} \mathrm{m}^{-2}$, with cholinergic events, fatigue and fever as DLTs. Again a near absolute lymphocytopaenia was noted (11 out of 12 patients). Flow cytometric studies demonstrated that BM had a deleterious effect on all lymphocyte subsets, but most prominently on B cells.

In a third phase I trial in which a single dose of BM every 3 weeks was studied, the MTD was determined at $280 \mathrm{mg} \mathrm{m}^{-2}$. The DLTs in this schedule were fatigue and cardiac toxicity (Rasschaert et al, 2007). At the MTD, ST segment and T-wave changes suggested ischaemic cardiac toxicity in three out of four patients and one patient experienced a QT prolongation. Non-specific

Table 3 Individual pharmacokinetic parameters of bendamustine in plasma

\begin{tabular}{|c|c|c|c|c|c|c|c|c|}
\hline Subject & $\begin{array}{c}\text { Dose (mg m } \\
\text { per day) }\end{array}$ & $t_{1 / 2}(\min )$ & $t_{\max }(\min )$ & $C_{\max }\left(\mathrm{ng} \mathrm{ml}^{-1}\right)$ & $\begin{array}{c}\text { AUC }_{\text {all }} \\
\left(\min \mathrm{ng} \mathrm{ml}^{-1}\right)\end{array}$ & $\underset{\left(\min \mathrm{ng} \mathrm{ml}^{-1}\right)}{A \cup C_{\mathrm{Inf}}}$ & $V_{d}\left(m / m^{-2}\right)$ & $\mathrm{Cl}\left(\mathrm{ml} \min \mathrm{m}^{-2}\right)$ \\
\hline 2 & 120 & 57.3 & 40 & 9011.5 & 490823.5 & $49 \mid 145.7$ & 24.3600 & 244.3 \\
\hline 6 & 140 & 30.7 & 30 & 9978.4 & 437716.8 & 437991.4 & 14.1583 & 319.6 \\
\hline 8 & 160 & 45.3 & 30 & 9966.1 & 448803.3 & 449333.0 & 23.2872 & 356.1 \\
\hline 13 & 160 & 60.0 & 50 & 24474.6 & 1800220.3 & | 805225.4 & 7.6750 & 88.6 \\
\hline 15 & 160 & 41.0 & 30 & 8797.7 & 444477.8 & 444631.4 & 21.2679 & 359.8 \\
\hline
\end{tabular}

Abbreviations: $\mathrm{AUC}_{\mathrm{Inf}}=\mathrm{A} \cup \mathrm{C}$ extrapolated to infinity; $\mathrm{AUC}_{\text {all }}=$ area under the plasma concentration time curve from time of dosing to last observation; $\mathrm{Cl}=$ clearance; $\mathrm{C}_{\text {max }}$ maximum peak concentration; s.d. = standard deviation; $\mathrm{tl} / 2=$ half life; $t_{\max }$, time to reach peak concentration; $\mathrm{Vd}=\mathrm{volume}$ of distribution. 
Table 4 Bendamustine in phase I (/II) studies

\begin{tabular}{|c|c|c|c|c|c|c|}
\hline Author & Phase & $n$ & Bendamustine regimen & MTD/RD ( $\left.\mathrm{mg} \mathrm{m}^{-2}\right)$ & DI $\left(\mathrm{mg} \mathrm{m}^{-2}\right.$ week $\left.^{-1}\right)$ & DLT \\
\hline Schöffski et al & 1 & 19 & $\mathrm{dl}, \mathrm{d} 8 \mathrm{q} 4$ weeks & $160 / 140$ & 80 & Mouth dryness, fatigue \\
\hline Schöffski et al & 1 & 12 & Weekly $\times 8$ & $80 / 60$ & 60 & Mouth dryness, fatigue, fever \\
\hline Rasschaert et al & । & 23 & dl q 3 weeks & $280 / 260$ & 87 & Fatigue, cardiac toxicity \\
\hline Bergmann et al CLL & $|/| \mid$ & 16 & $\mathrm{dl}, \mathrm{d} 2 \mathrm{q} 3-4$ weeks & $80 / 70$ & $47-35$ & Granulocytopaenia, infection \\
\hline Lissichkov et al CLL & $|/| \mid$ & 15 & $\mathrm{dl}, \mathrm{d} 2$ q 3-4 weeks & $110 / 100$ & 50 & $\begin{array}{l}\text { Bilirubinaemia } \\
\text { Diarrhoea }\end{array}$ \\
\hline Present study & 1 & 15 & $\mathrm{dl}, \mathrm{d} 2 \mathrm{q} 3$ weeks & $180 / 160$ & 107 & Thrombocytopaenia \\
\hline
\end{tabular}

T-wave changes and sinus tachycardia were seen at lower doses with that regimen.

The present phase I study allowed for a higher dose intensity (DI, $107 \mathrm{mg} \mathrm{m}^{-2}$ per week) at the recommended dose than found with other schedules used in phase I studies (Table 4) or those used in clinical practice so far. This observation is of importance since a concentration-dependent efficacy has been described in preclinical studies (Gandhi, 2002; Konstantinov et al, 2002; Schwänen et al, 2002).

The estimated mean values of BM's terminal half-live $\left(t_{1 / 2}\right)$ of $49.1 \mathrm{~min}$ and of its volume of distribution $\left(V_{\mathrm{d}}\right)$ of $18.31 \mathrm{~m}^{-2}$ are not different from those obtained in former pharmacokinetic evaluations (Matthias et al, 1995).

In the present study, all mean values of $t_{\max }$ and $t_{1 / 2}$ estimated for the metabolites $\mathrm{OH}-\mathrm{BM}, \gamma-\mathrm{OH}-\mathrm{BM}$ and $\mathrm{N}$-dimethyl-BM were in the range of 35-64 min and no dose dependency was evident for these metabolites.

No valid evaluation could be performed for Di-OH-BM due to too few data. Bendamustine and the hydrolysis products monohydroxy and dihydroxy BM are open to chemical hydrolysis. Therefore, the high variability of pharmacokinetic parameters should be interpreted with caution.

This was particularly true for the urinary $P_{k}$ data. As an example, the highly variable amount of $\mathrm{BM}$ determined in urine samples ranged from 0.8 to $50.2 \%$, expressed as percentage of the sum of all compounds quantified in this study. Therefore, for evaluation, we decided to summarise amounts of $\mathrm{BM}$ and the two hydrolysis products ( $\mathrm{OH}-\mathrm{BM}$ and $\mathrm{Di}-\mathrm{OH}-\mathrm{BM})$ assuming undesirable hydrolysis during sampling period and/or sample preparation before freezing. Hence, we calculated an amount excreted in urine of 5.2 and $1.6 \%$ for $\gamma$-OH-BM and $N$-dimethyl-BM, respectively, expressed as the sum of all compounds quantified in this study. These figures are in agreement with results observed in a previous $\mathrm{P}_{\mathrm{k}}$ study (Teichert et al, 2006).

In conclusion, BM hydrochloride given on a day $1+2 \mathrm{q} 3$ weeks schedule has predictable haematologic DLT and acceptable nonhaematologic toxicities. Nevertheless, as in other phase I experiences, fatigue remains an unpleasant side effect also with this schedule. The recommended dose of $160 \mathrm{mg} \mathrm{m}^{-2}$ per day seems to be safe and allows for a relatively high-dose intensity in comparison with other schedules. However, considering the overall low number of treatment cycles per patient in this phase I study, additional information with this schedule in a more favourable patient group seems warranted.

\section{ACKNOWLEDGEMENTS}

We thank Joke Dyck and Veerle Nys for data management, Dr Möller (Bioproof, Munich) and Professor Preiss (University of Leipzig) for the analytical measurements and data supply and ribosepharm $\mathrm{GmbH}$, Munich, Germany for supporting this study.

\section{REFERENCES}

Barmam Balfour JA, Goa KL (2001) Bendamustine. Drugs 61: 631-640 Bergmann M, Goebeler M, Herold M, Emmerich B, Wilhelm M, Ruelfs C, Boening L, Hallek M (2005) Efficacy of bendamustine in patients with relapsed or refractory chronic lymphocytic leukemia: results of a phase I/ II study of the German CLL Study Group. Haematologica 90: 1357 - 1364

Bezek S, Kukan M, Scasnár V, Lukásková M, Trnovec T (1996) Selective uptake of the anticancer drug bendamustine by liver and kidney tissues following its intravenous administration to mice. Methods Find Exp Clin Pharmacol 18: $117-122$

Bezek S, Scasnár V, Trnovec T, Grupe R (1991) Hepatobiliary elimination of bendamustin (Cytosan ${ }^{\mathbb{R}}$ ) in rats. Pharmazie 46: $810-811$

Bremer K (2002) High rates of long-lasting remissions after 5-day bendamustine chemotherapy cycles in pre-treated low-grade nonHodgkin's-lymphomas. J Cancer Res Clin Oncol 128: 603 -609

Chow KU, Boehrer S, Geduldig K, Krapohl a, Hoelzer D, Mitrou P, Weidmann E (2001) In vitro induction of apoptosis of neoplastic cells in low-grade non-Hodgkin's lymphomas using combinations of established cytotoxic drugs with bendamustine. Haematologica 86: 485-493

Chow KU, Nowak D, Boerher S, Ruthardt M, Knau A, Hoelzer D, Mitrou P, Weidmann E (2003) Synergistic effects of chemotherapeutic drugs in lymphoma cells are associated with down-regulation of inhibitor of apoptosis proteins (IAPs), prostate-apoptosis-response-gene 4 (Par-4), death-associated protein (Daxx) and with enforced caspase activation. Biochem Pharmacol 66: 711-724

Friedberg J, Cohen P, Kerr R, Robinson KS, Forero-Torres A, van der Jagt R, Camacho E, Hainsworth J, Roeck B, Multani P (2004) SDX-105 demonstrates a high response as a single-agent with acceptable safety in rituximab-refractory, relapsed indolent or transformed non-Hodgkin's lymphoma (NHL). ASH Annual meeting abstracts 2004. Blood 104(11): [abstract 2480]

Gandhi V (2002) Metabolism and mechanisms of action of bendamustine: rationales for combination therapies. Sem Oncol 29(4 Suppl 13): 4- 11

Heider A, Niederle N (2001) Efficacy and toxicity of bendamustine in patients with relapsed low-grade non Hodgkin's lymphomas. AntiCancer Drugs 12: 725-729

Herold M, Schulze A, Niederwieser D, Franke A, Fricke HJ, Richter P, Freund M, Ismer B, Dachselt K, Boewer C, Schirmer V, Weniger J, Pasold R, Winkelmann C, Klinkenstein C, Schulze M, Arzberger H, Bremer K, Hahnfeld S, Schwarzer A, Müller C, Müller Chr (2006) Bendamustine, vincristine and prednisone (BOP) versus cyclophosphamide, vincristine and prednisone (COP) in advanced indolent non-Hodgkin's lymphoma and mantle cell lymphoma: results of a randomised phase III trial (OSHO\# 19). J Cancer Res Clin Oncol 132: 105-112

Höffken K, Merkle Kh, Schönfelder M, Anger G, Brandtner M, Ridwelski K, Seeber S (1998) Bendamustine as salvage treatment in patients with advanced progressive breast cancer: a phase II study. J Cancer Res Clin Oncol 124: $627-632$

Horn U, Härtl A, Güttner J, Hoffmann H (1985) Toxicity of the alkylating agent Bendamustin. Arch Toxicol 8(Suppl): 504-506

Kanekal S, Crain B, Elliot G (2004) SDX-105 (Treanda ${ }^{\mathrm{TM}}$ ) enhances the tumor growth inhibitory effect of rituximab in daudi lymphoma 
xenografts, ASH annual meeting abstract 2004. Blood 104(11): [abstract 4580]

Konstantinov SM, Kostovski A, Topashka-Ancheva M, Genova M, Berger MR (2002) Cytotoxic efficacy of bendamustine in human leukemia and breast cancer cell lines. J Cancer Res Clin Oncol 128: 271-278

Leoni LM, Bailey B, Reifert J, Niemeyer C, Bendall H, Dauffenbach L, Kerfoot C (2004) In vitro and ex vivo activity of SDX-105 (bendamustine) in drug-resistant lymphoma cells. Proc Am Assoc Cancer Res 45, [abstract 1215]. (As indicated on the website of the AACR)

Lissitchkov T, Arnaudov G, Peytchev D, Merkle K (2006) Phase I/II study to evaluate dose limiting toxicity, maximum tolerated dose, and tolerability of bendamustine $\mathrm{HCl}$ in patients with $\mathrm{B}$-chronic lymphocytic leukaemia (Binet stages B and C) requiring therapy. J Cancer Res Clin Oncol 132: 99- 104

Matthias M, Preiss R, Sohr R, Possinger K (1995) Pharmacokinetics of bendamustin in patients with malignant tumors. Proc Am Soc Clin Oncol 14: 458 (abstract 1476)

Niemeyer C, Bailey B, Reifert J, Bendall H, Corbeil J, Leoni LM (2004) SDX105 (Bendamustine) is a clinically active chemotherapeutic agent with a distinct mechanism of action. Proc Am Assoc Cancer Res 45, [abstract 1129]. (as indicated on the website of the AACR)

Ozegowski W, Krebs D (1963) w-[bid-( $\beta$-chloroethyl)-amino-benzimazolyl(2)]-propionic or butyric acids as potential cytotoxic agents. J Pract Chem 20: $178-186$

Pönisch W, Mitrou PS, Merkle K, Herold M, Assmann M, Wilhelm G, Dachselt K, Richter P, Schirmer V, Schulze A, ubert R, Harksel B, Grobe N, Stelzer E, Schulze M, Bittrich A, Freund M, Pasold R, Friedrich T, Helbig W, Niederwieser D (2006) Treatment of bendamustine and prednisone in patients with newly diagnosed multiple myeloma results in superior complete response rate, prolonged time to treatment failure and improved quality of life compared to treatment with melphalan and prednisone-a randomized phase III study of the East German Study Group of Hematology and Oncology (OSHO). J Cancer Res Clin Oncol 132(4): $205-212$

Preiss R, Matthias M, Merkle KH (1998) Pharmacological and clinical data of bendamustine. Proceedings of the 17th International Cancer Congress Rio de Janeiro, 24-28 August 1998, Monduzzi Editore S.p.A. Bologna: pp. $1637-1640$

Pyke K, Tschakovsky M (2005) The relationship between shear sterss and flow-mediated dilation: implications for the assessment of endothelial function. J Physiol 568: 357-369

Rasschaert M, Schrijvers D, Van den Brande J, Dyck J, Bosmans J, Merkle $\mathrm{KH}$, Vermorken JB (2007) A phase I study of bendamustine hydrochloride administered once every three weeks in patients with solid tumors. Anti Cancer Drugs 18: 587-595

Reck M, Haering B, Koschel G, Kaukel E, von Pawel J, Gatzemeier U (1998) Chemotherapie des fortgeschrittenen nicht-kleinzelligen und kleinzelligen bronchialkarzinoms mit bendamustin - Eine phase II Studie. Pneumologie 52: 570-573

Rummel M, Al-Batran S, Kim S, Welslau M, Hecker R, Kofahl-Krause D, Josten K, Dürk H, Rost A, Neise M, von Grünhagen U, Chow K, Hansmann M, Hoelzer D, Mitrou P (2005a) Bendamustine plus rituximab is effective and has a favorable toxicity profile in the treatment of mantle cell and low-grade non-Hodgkin's lymphoma. J Clin Oncol 23: $3383-3389$

Rummel M, Al-Batran S, Welslau M, Kofahl-Krause D, Duerk H, Hoelzer D, Mitrou P (2005b) Bendamustine and rituximab act synergistically in vitro and are effective in the treatment of relapsed or refractory indolent and mantle cell lymphomas. Proc Am Soc Clin Oncol 24: 576s (abstract 6565).

Schmittel A, Knodler M, Hortig P, Schulze K, Thiel E, Keilholz U (2007) Phase II trial of second-line bendamustine chemotherapy in relapsed small cell lung cancer patients. Lung Cancer 55(1): 109-113

Schöffski P, Hagedorn T, Grünwald V, Paul H, Merkle K, Kowalski R, Ganser A (2000a) Repeated administration of short infusions of bendamustine: a phase I study in patients with advanced progressive solid tumours. J Cancer Res Clin Oncol 126: $41-47$

Schöffski P, Seeland G, Engel H, Grünwald V, Paul H, Merkle K (2000b) Weekly administration of bendamustine: a phase I study in patients with advanced progressive solid tumours. Ann Oncol 11: 729-734

Schrijvers D, Vermorken JB (2002) Phase I studies with bendamustine: an update. Semin Oncol 29(4 Suppl 13): 15-18

Schwänen C, Hecker T, Hübinger G, Wölfe M, Rittgen W, Bergmann L Karakas T (2002) In vitro evaluation of bendamustine induced apoptosis in B-chronic lymphocytic leukemia. Leukemia 16: 2096-2105

Strumberg D, Harstrick A, Doll K, Hoffmann B, Seeber S. (1996) Bendamustine hydrochloride activity against doxorubicin-resistant human breast carcinoma cell lines. Anticancer Drugs 7: 415-421

Teichert J, Baumann F, Chao Q, Franklin C, Bailey B, Hennig L, Caca K, Schoppmeyer K, Patzak U, Preiss R (2006) Characterization of two phase I metabolites of bendamustine in human liver microsomes and in cancer patients treated with bendamusitne hydrochloride. Cancer Chemother Pharmacol September 7 [E-pub ahead of print]

Teichert J, Mockel J, Pönisch W, Seidel A, Lotfi M, Matthias M (2003) Influence of hepatic and renal function on the pharmacokinetics of bendamustine. Int J Clin Pharmacol Ther 41: 564

Teichert J, Sohr R, Baumann F, Hennig L, Merkle K, caca K, Preiss R (2005) Synthesis and characterization of some new phase II metabolites of the alkylator bendamustine and their identification in human bile, urine and plasma from patients with cholangiocarcinoma. Drug Metab Dispos 33: 984-992

Von Minckwitz G, Chernozemsky I, Sirakova L, Chilingirov P, Souchon R, Marschner N, Kleeberg U, Tsekov C, Fritze D, Thomssen C, Stuart N, Vermorken JB, Loibl S, Merkle Kh, Kaufmann M (2005) Bendamustine prolongs progression-free survival in metastatic breast cancer (MBC): a phase III prospective, randomized, multicenter trial of bendamustine hydrochloride, methotrexate and 5-fluorouracil (BMF) versus cyclophosphamide, methotrexate and 5-fluorouracil (CMF) as first-line treatment of MBC. Anticancer Drugs 16(8): $871-878$

Weber H, Amlacher R, Preiss R, Hoffmann H (1991) Pharmakokinetik von bendamustin (Cytostasan ${ }^{\mathbb{R}}$ ) in B6D2 $\mathrm{F}_{1}$-Mäusen. Pharmazie 46: 589 - 591

Weidmann E, Kim S, Rost A, Schuppert H, Seipelt G, Hoelzer D, Mitrou P (2002) Bendamustine is effective in relapsed or refractory aggressive non-Hodgkin's lymphoma. Ann Oncol 13: 1285-1289

Zulkowski K, Kath R, Semrau R, Merkle Kh, Höffken K (2002) Regression of brain metastases from breast carcinoma after chemotherapy with bendamustine. J Cancer Res Clin Oncol 128: 111-113 